\title{
PROGRAM PENGEMBANGAN KEWIRAUSAHAAN DI PERGURUAN TINGGI
}

\author{
Hadi Pajarianto ${ }^{1^{*}}$, Andi Muhammad Adigoena ${ }^{2}$, Imran Ukkas ${ }^{3}$, Imam Pribadi ${ }^{4}$ \\ ${ }^{1 *}$ Program Studi Pendidikan Guru PAUD, Universitas Muhammadiyah Palopo \\ ${ }^{2}$ Program Studi Pendidikan Guru PAUD, Universitas Muhammadiyah Palopo \\ ${ }^{3}$ Program Studi Manajemen, Universitas Muhammadiyah Palopo \\ ${ }^{4}$ Program Studi Bimbingan dan Konseling, Universitas Muhammadiyah Palopo \\ Corresponding author : \\ E-mail : hadipajarianto@umpalopo.ac.id
}

Diterima 26 Oktober 2019, Disetujui 6 November 2019

\begin{abstract}
ABSTRAK
Tujuan Program Pengembangan Kewirausahaan Universitas Muhammadiyah Palopo adalah menghasilkan mahasiswa dan alumni berwirausaha yang mandiri berbasis iptek, melalui program yang terintegrasi dengan melibatkan dosen, narasumber, mahasiswa, dan calon alumni. Kegiatan program yang dapat menjadi solusi bagi permasalahan kewirausahaan, antara lain (1) pengembangan jiwa wirausaha dan motivasi bisnis, (2) pelatihan manajemen dan skills usaha bagi tenant, (3) pengembangan jejaring dan kelembagaan wirausaha; (4) konsultasi dan afirmasi bisnis, (5) membuka akses modal untuk berwirausaha (6) memfasilitasi tenant dalam berwirausaha untuk menghasilkan wirausaha baru. Program ini melakukan pembinaan kewirausahaan kepada 20 tenant mahasiswa dan alumni. Pada akhir program, sebanyak 6 tenant mahasiswa dan alumni menjadi wirausaha baru pada berbagai bidang, dengan produk berkualitas yang dapat bersaing dengan produk sejenis. Melalui daya inovasi dan bisnis, bidang yang digeluti oleh tenant yang mandiri adalah (1) Bua Hydrofarm; (2) gerobak kuliner; (3) edubooks store; (4) edureptil; (5) kuliner KriboU; dan (6) busana muslimah dan foto copy.
\end{abstract}

Kata kunci: kewirausahaan, bisnis, tenant

\begin{abstract}
The objective of Entrepreneur Development Program is to create the students and alumni who can set up their own business autonomously based on science and technology. The program is conducted integrative by involving the lecturers, the experts, the students, and the alumni. The programs that can be a solution of entrepreneurship problems are: (1) development of entrepreneurship spirit and business motivation, (2) business skill and management training for tenants, (3) development of business network and institution, (4) business consultation and affirmation, (5) discovering the capital access for business, and (6) facilitating the tenants to develop their business. This Program involves 20 tenants of both students and alumni. At the end of this program, there are six tenants become new businessman/woman in various sectors with good quality and competitive products. Through business incubator, the tenants develop their business in: (1) Hydro farm; (2) culinary cart; (3) edu-book store; (4) edu-reptile; (5) KriboU culinary; and (6) muslimah fashion and photocopy.
\end{abstract}

Keywords: enterpreneurship, business, tenant

\section{PENDAHULUAN}

Salah satu ciri dari edupreneur yang banyak dikembangkan adalah adalah kewirausahaan yang berbasis pendidikan (Ma'rufi, llyas, Anas, \& Yusrin, 2018), pada beberapa daerah diharapkan dapat memberikan kontribusi yang cukup besar terhadap perkembangan dunia kewirausahaan dan Usaha Mikro Kecil di dalam kampus dan masyarakat luas (Arief, Puji Astuti, \& Andriyanto, 2016). Beberapa bentuk wirausaha tersebut antara lain, jasa analisis data peneltian, bimbingan belajar, jasa tour pariwisata dan budaya, konsultan pendidikan, dan komik lontara sebagai buku bacaan dan semua produk pendidikan tersebut mengandung nilai bisnis yang sangat menarik apabila dikembangkan khususnya untuk pendidikan.

Dobon dalam (Sundoro \& Ardianti, 2014) mengemukakan bahwa motivasi kewirausahaan terdiri dari enam kelompok besar atau dimensi motivasi yaitu: (1) personal, 
yakni untuk mendapatkan penghargaan (need for achievement), keinginan untuk mendapatkan kebebasan (need for independence) dan keinginan untuk kekayaan (desire for wealth); (2) keterkaitan motivasi dengan pengetahuan ilmiah (scientific), perkembangan ilmu pengetahuan adalah salah satu motivasi utama peneliti selama pengembangan karir mereka (Etzkowitz, 1998);

(3) keterkaitan motivasi dengan kesempatan (opportunity); (4) keterkaitan motivasi dengan keadaan sumber daya (resource); (5) keterkaitan motivasi dengan inkubator organisasi (incubator organization); dan (6) keterkaitan motivasi dengan jaringan sosial (social network).

Pada perguruan tinggi, kendala utama mahasiswa adalah time manager yang tepat dan akurat, mengatur waktu dengan baik karena pada prinsipnya bisnis harus berinteraksi dengan sistem yang saling berkaitan (Ismail, 2004). Biasanya, mahasiswa kurang disiplin dalam mengatur waktu antara kegiatan akademik dengan kegiatan usaha yang dikembangkan terutama banyaknya tugas kuliah yang harus diselesaikan. Selain itu, mahasiswa terkadang tidak percaya diri dalam mempromosikan produk yang dihasilkannya, kurang mampu menjalin interaksi dengan khalayak yang menjdi pasarnya yang diakibatkan oleh kurangnya kemampuan komunikasi bisnis, padahal dalam dunia bisnis pola kemitraan sangat berperang penting dalam kemajuan dunia usaha (Widyani, 2013).

Secara prinsipil, input, proses, dan intensitas yang tidak kenal menyerah, akan sangat menentukan masa depan wirausahawan. Sikap kreatif dan inovatif juga perlu ada dalam jiwa wirausahawan. Akan tetapi sikap tersebut tidak ada artinya bila tidak ada sikap ulet, karena seseorang yang memiliki pemikiran yang kreatif serta inovatif pasti juga bersikap ulet. Secara logika orang kreatif dan inovatif akan selalu mencoba dengan kata lain mereka pasti akan ulet dalam mencari cara untuk mendapatkan produk yang unggul.

Berdasarkan Gambar 1 dari sisi input dapat dijelaskan tentang: (1) peluang lingkungan kampus dapat mendukung melakukan optimalisasi potensi sumber daya, (2) karakter ulet dalam berusaha menjadi modal para tenant untuk melakukan konsolidasi sumber saya yang ada, (3) dalam konteks kampus UPPK dapat menjadi media konsolidasi para tenant dalam melakukan pelembagaan aktivitas perubahan sosial di kampus, (4) keunikan bisnis konsep yang dimunculkan oleh para tenant yaitu mereka memiliki gagasan inovatif dalam menciptakan nilai bisnis yang tidak hanya berorientasi profit tetapi juga menjawab permasalahan sosial desa, dan (5) sumber daya, kemampuan kedua para tenant dalam mengidentifikasi,memobilisasi dan meningkatkan kapasitas maupun produktifitas sumber daya kampus dan lingkungan eksternal menjadi bagian penting untuk implementasi ide/gagasan bisnis.

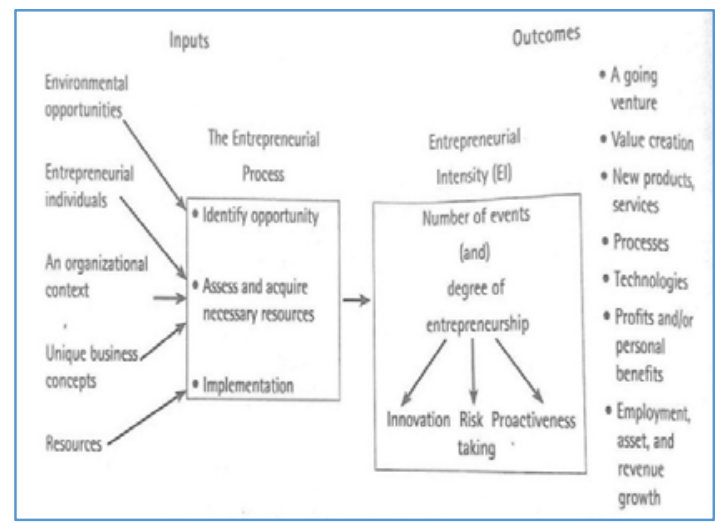

Gambar 1. Input, Proses, dan Outcomes dalam Berwirausaha (Kuratko, 2014)

Dari kelima input tersebut kemudian berproses sesuai tingkat intensitas implementasi kewirausahaan yang harus dioperasionalkan oleh para tenant. Aspek inovasi, kesediaan mengambil risiko dan proaktif baik secara bisnis maupun sosial menjadi bagian yang sangat penting yang menentukan keberlanjutan hasil (outcomes) dari kewirausahaan yang ada. Ragam hasil (outcomes) berupa aktivitas bisnis (usaha), nilai dan manfaat dari usaha baik produk maupun jasa dengan dukungan teknologi mampu meningkatkan pertumbuhan pendapatan dan aset termasuk membuka kesempatan kerja.

Pada kegiatan PPK, pelaksana dan tenant terlibat kolaborasi dan saling mendukung satu dengan yang lain, sehingga target yang telah ditetapkan dapat tercapai. Target pada kegiatan PPK ini adalah sebagai berikut: (1) meningkatkan pengetahuan tenant, termasuk diantaranya dalam aspek manajemen, kuantitas dan kualitas produksi; (2) menemukan model inkubator bisnis yang sesuai dengan ciri masyarakat kampus; (3) mendiseminasikan program dalam jurnal maupun media elektronik, agar terpublikasi secara nasional; dan (4) menciptakan minimal 5 wirausahawan yang mandiri di bidangnya masing-masing.

\section{METODE}

Rekruitment (seleksi) tenant program PPK ini pada tahun pertama (2019) diikuti oleh 
5 (lima) tenant yang telah merintis usaha, dan 15 (lima belas) tenant wirausaha baru, keseluruhan. Proses seleksi calon tenant dilakukan secara bertahap sebagai berikut: (1) sosialisasi kepada mahasiswa yang berminat di bidang kewirausahaan, (2) Melakukan seleksi (recruitment test) terhadap pendaftar program Inkubator Bisnis Mahasiswa. (3) sejumlah (30) tiga puluh mahasiswa yang sudah berhasil lolos dari recruitment test mengikuti program perkuliahan kewirausahaan, tapi hanya 20 (dua puluh) mahasiswa dengan urutan ranking terbaik yang diperbolehkan melanjutkan untuk mengikuti program entrepreneurship capacity building, yaitu (1) diklat kewirausahaan, (2) magang kewirausahaan, dan (3) Inkubator kewirausahaan. Dari 20 mahasiswa yang digodok dalam program pembentukan kapasitas wirausaha dapat dihasilkan 5-8 mahasiswa wirausaha baru mandiri per tahun yang siap berkompetisi di masyarakat (bussines establishment).

$$
\text { Metode pelaksanaan PPK }
$$

menggunakan pendekatan SLA (The Sustainable Livelihood Approach), yang meliputi tahap persiapan, pelaksanaan, serta evaluasi dan monitoring. Pemberdayaan masyarakat dengan metode the Sustainable Livelihood Approach (SLA) pada dasarnya adalah upaya pelibatan (partisipasi) masyarakat/keluarga/komunitas masyarakat untuk belajar dan beraktivitas secara berkelanjutan dengan cara unik mereka menjalani hidup dalam rangka meningkatkan kualitas hidup mereka. Selain itu juga diperkuat dengan metode PALS (Parcipatory Action Learning) yang menitikberatkan pada transformasi kegiatan menuju pada perubahan ke arah jiwa enterpreneurship mahasiswa yang lebih baik.

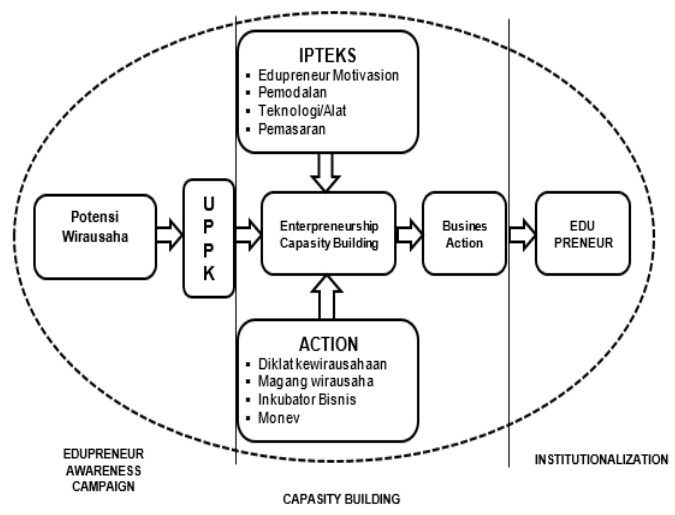

Gambar 2. Pendekatan Pelaksanaan PPK (adaptasi dari Budiyanto, 2015)
Dari gambar 2. tahapan kegiatan PPK secara garis besar terdiri atas 3 (tiga), yakni, pertama kampanye kesadaran berwirausaha. Tahap ini sangat penting dalam kegiatan PPK, karena bertujuan membentuk sikap, perilaku, dan nilai edupreneurship. Pola pikir yang terfokus pada profesi tertentu harus diimbangi dengan proses berpikir yang kreatif, inovatif, dalam menghadapi dinamika dunia kerja yang berubah sangat cepat. Kedua, pembangunan kapasitas dimana tenant akan dibimbing tentang manajemen usaha, manajemen produksi, dan diberikan skill untuk dapat menganalisis dan menyusun solusi atas berbagai hambatan usahanya. Sifatnya dapat kordinatif, konsultatit, dan afirmatif dilakukan berkesinambungan dengan berbagai lembaga yang memiliki konsentrasi terhadap pengembangan kewirausahaan. Ketiga, pelembagaan, untuk menciptakan jeringan dan mitra kerjasama antara kampus, tenant, dan lembaga yang dapat prosesnya memanfaatkan keunggulan lembaga mitra.

\section{PEMBAHASAN}

Program

Pengembangan

Kewirausahaan tahun pertama ini diikuti oleh 20 (dua puluh) tenant yang dilaksanakan mulai tanggal 01 Juni - 30 Nopember 2019. Adapun yang menjadi pokok kegiatan pengabdian ini adalah:

\section{Keunggulan Produk Tenant}

Tenant yang terlibat dalam Program Pengembangan Kewirausahaan terdiri dari 5 orang alumni, dan 15 orang mahasiswa aktif yang tersebar di dua fakultas. Wirausaha baru ini sebagai calon yang akan dilatih melalui program terintegrasi dengan kreativitas, baik secara internal maupun eksternal dalam rangka menjadi wirausaha mandiri pada tahun 2019. Pada tahun pertama, telah dihasilkan 6 orang wirausaha mandiri.

Sebelum dilaksanakan rangkaian kegiatan PPK, UPPK melakukan inventarisasi terhadap mahasiswa yang sudah, sedang, dan memiliki kemauan untuk berwirausaha. Hasil inventarisasi tersebut kemudian dilakukan pemantauan di lapangan dan wawancara untuk memastikan kesiapannya mengikuti program pengembangan kewirausahaan. Mereka diberikan formulir yang berisi nama, nomor kontak, usaha yang digeluti atau akan dilakukan, dan tahun mereka merintis usaha tersebut. Selain telah tersedianya UPPK dan inkubator bisnis sebagai wahana belajar, beberapa pelatihan juga bisa menjadi fasilitasi mahasiswa untuk belajar berwirausaha dan berinovasi untuk menghasilkan produk baru. Beberapa 
mahasiswa dan alumni sudah merintis usaha baru, selain itu beberapa orang mahasiswa masih memperdalam minat dan produk yang akan mereka masukkan dalam kegiatan bisnis.

Produk yang dihasilkan pada kegiatan PPK ini memiliki ciri khas dan keunggulan masing-masing. Diantara produk yang memiliki keunggulan adalah sayuran hidroponik yang dihasilkan oleh Bua Hydrofarm yang sudah memasuki pasar Luwu Raya, dan jika dibina secara simultan bukan tidak mungkin akan dapat memasuki skala industri. Demikian juga gerobak kuliner Sarang Palacci yang memiliki prospek yang sangat baik seiring dengan perkembangan Palopo sebagai kota jasa. Demikian juga Edubooks Store di kampus Universitas Muhammadiyah Palopo, selain akan berdampak pada ekonomi juga akan menguatkan literasi kampus. Edureptil sebagai salah satu tenant, juga memiliki prospek invertasi yang menjanjikan selain sebagai wadah komunitas pecinta reptil dan edukasi konservasi.

Dari penilaian kinerja bisnis, secara umum mereka memiliki motivasi tinggi untuk memperoleh pengalaman wirausaha dan berpikir kreatif. Kreativitas sangat penting agar inovasi produk berjalan secara terus menerus sesuai kemajuan zaman.

\section{Potensi dan Nilai Produk \\ Ridwan-Bua Hydrofarm}

Ridwan lahir pada 03 Juni 1994, anak keempat dari 5 bersaudara. Awal ketertarikan Ridwan pada pertanian sayuran sistem hidroponik berawal dari sifatnya yang serba ingin tahu dan mencoba sesuatu, sehingga membuatnya sering melakukan ujicoba dan beberapa kali mengalami kegagalan. Salah satu sistem bercocok tanam yang menjawab kebutuhan manusia untuk dapat bercocok tanam di lingkungan yang sangat sempit adalah sistem bercocok tanam dengan hidroponik.

Saat ini, Ridwan telah memiliki 2 buah Green House merupakan bantuan dari kegiatan PPK. Green House 1 memiliki kapasitas \pm 1.000 lubang, dan Green House 2 memiliki kapasitas 9.00 lubang. Sistem yang digunakan ada dua, yakni NFT dan DFT. Perhitungan bisnisnya sederhana, 1.900 lubang berarti 1.900/15= 126 $\mathrm{kg}$, dalam masa 35-45 hari. Harga selada dan sawi Bua Hydrofarm dijual dengan harga Rp. 50.000 x 126 kg= Rp. 6.300.000. Saat ini pemasaran dilakukan secara langsung, pelanggan datang atau diantarkan, juga melalui sosial media. Pelanggannya adalah para penjual burger yang menjamur di Luwu Raya, dan salah satunya juga adalah binaan PPK.
Sosial media yang digunakan adalah instagram dan facebook.

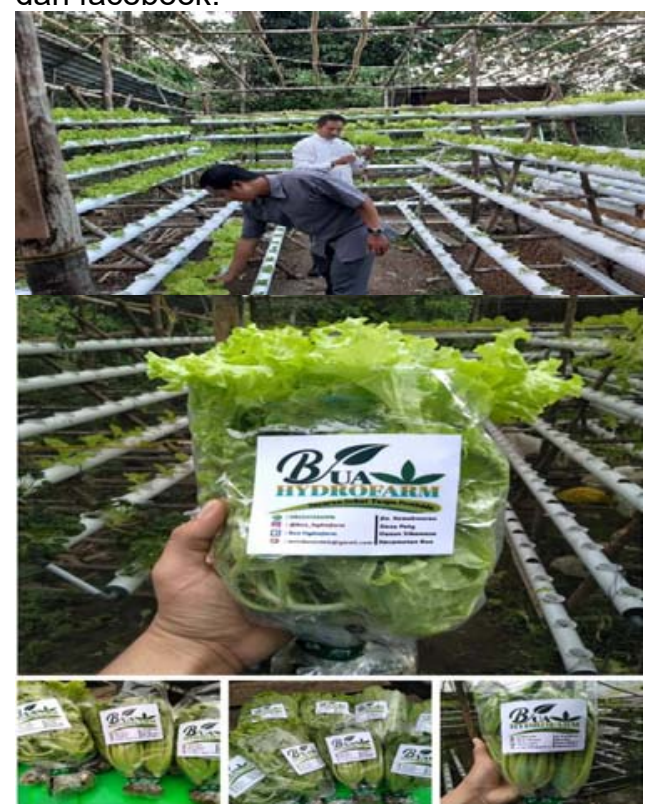

Gambar 3. Green House Bua Hydrofarm

\section{Amar-Gerobak Kuliner Sarang Palacci}

Amar adalah salah satu karyawan sebuah lembaga Finance yang sangat terkenal di Indonesia dengan posisi yang cukup menjanjikan. Hingga pada tahun 2017, akhirnya memutuskan untuk resign dari perusahaan tempatnya bekerja dan memulai berwirausaha dengan 1 gerobak dorong yang dinamakan Sarang Palacci. Sarang Palacci adalah usaha kuliner dengan memanfaatkan pusat keramaian di lapangan Pancasila kota Palopo. Sarang Palacci menyediakan aneka sandwich dan berbagai jenis minuman kekinian.

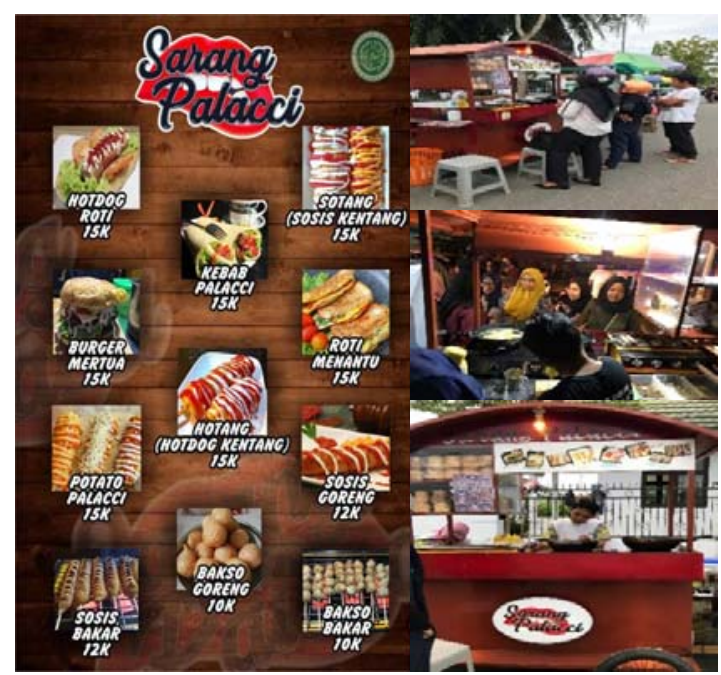

Gambar 4. Gerobak Kuliner Sarang Palacci 
Pada awalnya, Sarang Palacci hanya memiliki 1 orang karyawan, tetapi setelah diberikan intervensi melalui kegiatan PPK, karyawannya bertambah menjadi 3 orang. Omset setiap bulan rata-rata $10-12$ juta per bulan, gaji karyawan 1,2 juta perbulan. Pemerintah kota Palopo telah berhasil menata kawasan Lapangan Pancasila lebih indah, nyaman dan rapi. Dahulu, lapangan Pancasila hanya tempat untuk upacara dan olah raga. Tetapi saat ini telah menjadi pusat komunitas kuliner yang sangat ramai dan menjanjikan bagi bisnis pelaku ekonomi kreatif atau UMKM (Usaha Mikro Kecil Menengah).

\section{Tri Putra-Edureptil}

Mengusung slogan "hobby, konservasi, dan investasi" Edureptil didirikan oleh Tri Putra Ramadhani dan Wisnu Budiarti. Perkembangan komunitas reptil pada berbagai daerah di Indonesia makin maju pesat. Selain sebagai hobi dan kegiatan bersosialisasi, kini reptil juga dijadikan sebagai investasi. Salah satu contohnya adalah Iguana. Bayi green iguana dibanderol Rp 300 ribu per ekor, red iguana 750 ribu, dan blue iguana 5 juta rupiah. Pada kegiatan PPK, tim pengusul memfasilitasi indukan iguana 2 ekor dengan harga per ekor Rp. 2.500.000. Saat ini masih dalam proses perkawinan, dan diharapkan akan bertelur sebanyak 70-an, dengan tingkat keberhasilan 50 persen saja, maka akan ada 30 bayi iguana. Tri Putra Ramadhani telah memiliki keterampilan dalam mengawinkan, merawat telur, penetasan, dan perlakuan terhadap bayi iguana. Komunitas seperti ini, diharapkan dapat menjadi sarana edukasi, bahwa hobi dapat disalurkan secara positif dengan memperhatikan habitat hewan yang dipeliharanya, agar tidak punah.

\section{Ahyar Ismail-Edubooks Store}

Dunia kampus, identik dengan buku, foto kopi, penjilidan, dan aktivitas intelektual dan administrasi lainnya. Ahyar Ismail, memulai usaha jasa print dan pengetikan di kampus Jl. Jenderal Sudirman Km. 3 Binturu kota Palopo. Usaha tersebut sejak tahun 2016 sampai saat ini masih berjalan dengan baik, dengan segmentasi mahasiswa yang berjumlah 3.000 orang. Saat ini, edubooks store yang dijalankan Ahyar Ismail telah eksis di kampus Universitas Muhammadiyah Palopo, dengan memanfaatkan tenaga teman-temannya (karyawan) yang bergantian menjaga toko kecil tersebut. Saat ini, edubooks store bukan hanya menjual buku semata, tetapi juga melakukan gerakan literasi di kalangan mahasiswa. Terdapat satu rak buku yang dapat dibaca oleh pembeli, dan di rak yang lain adalah yang dikomersilkan. Rata-rata pengunjung dalam setiap hari tidak kurang dari 25 orang mahasiswa, baik yang belanja buku, memanfaatkan jasa pengetikan, maupun untuk membaca buku gratis yang disiapkan.

\section{Bahraini-Kribou}

KriBoU adalah singkatan Keripik dan Bolu Uwi, yang berhasil memenangkan Program Kreatifitas Mahasiswa (PKM) tahun 2017. Bahraini yang bermukim di Batusitanduk kec. Walenrang kabupaten Luwu melihat uwi yang banyak tumbuh di gunung sekitar kediamannya masih tidak dimanfaatkan dengan maksimal. Uwi merupakan salah satu bahan pangan tertua di dunia. Di daerah asalnya, produksi dan pemanfaatan uwi hasil budidaya tidaklah menonjol, tetapi masih ada yang menggunakannya sebagai makanan pokok.

Walenrang Utara adalah salah satu Kecamatan yang terletak di kabupaten Luwu, Propinsi Sulawesi Selatan. Secara geografis Walenrang Utara terletak dibagian utara Ibukota Kabupaten Luwu (Belopa). Potensi yang dimiliki Walenrang Utara adalah pertanian, khususnya lahan persawahan. Selain potensi pertanian masyarakat Walenrang Utara memiliki lahan tanah perkebunan yang sangat subur yang mampu menghasilkan uwi kualitas super. Uwi tumbuh subur secara sporadis di pekarangan warga dan tidak memerlukan perawatan.

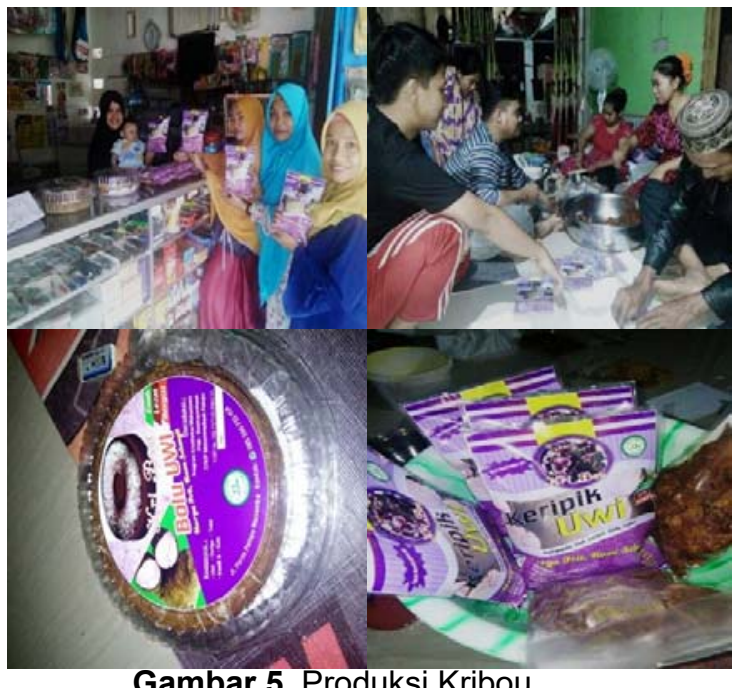

Gambar 5. Produksi Kribou

Keunggulan dari produk ini adalah keripik dan bolu yang dihasilkan memiliki cita rasa yang khas karena memakai uwi sebagai bahan utama. Manfaat bagi kesehatan apabila mengkonsumsi uwi pun beragam, seperti kadar gula lebih rendah dari pada nasi, sehingga 
dapat digunakan sebagai alternatif makanan sumber karbohidrat (khusus untuk rasa original) bagi penderita Diabetes Melitus, serta banyak mengandung vitamin seperti vitamin B1 dan vitamin $\mathrm{C}$ yang berguna untuk menjaga dan meningkatkan daya tahan tubuh. Kandungan rill dari produk akan dikembangkan dengan bekerjasama dengan laboratorium gizi, untuk dicantumkan pada label produk. Ada 3 (tiga) rasa keripik yang kami tawarkan yaitu rasa original (asli), manis dan pedas manis sedangkan kue bolu dapat divariasikan dalam berbagai rasa, seperti; rasa keju, original, dan gula merah.

\section{Asmila-Buket, Busana Muslimah} Indonesia mayoritas penduduknya beragama Islam, sehingga busana muslim dan kerudung di negara ini sangat di butuhkan, sehingga usaha-usaha yang mengkhususkan berjualan busana muslim ini semakin berkembang, baik itu yang memproduksi busana muslim dengan merk sendiri sampai toko-toko yang menjual busana muslim samasama kebanjiran order. Bagi para pemula, memulai berbisnis di bidang ini peluangnya masih sangat terbuka lebar, asalkan mengikuti trend yang sedang ramai dijual. Asmila, salah seorang mahasiswa STKIPM Palopo memanfaatkan posisi geografis rumahnya yang berdekatan dengan kampus IAIN Palopo sebagai pusat bisnis boket wisuda, pakaian, dan foto copy.

Usaha yang dilakukan Asmila sebenarnya merupakan perpaduan antara kebutuhan administrasi pendidikan mahasiswa seperti foto kopi, jilid, dan pakaian. Asmila menggunakan Ipteks untuk produk beberapa aksesoris dari bahan bekas (daur ulang) dan mendesain sendiri kerudung dan mukenah yang dibuat dari bahan pilihan sesuai selera remaja dan orangtua. Kaos anak-anak dibuat dengan bekerjasama dengan tukang sablon dengan desain yang dibuat sendiri. Asmila memiliki bakat mendesain busana dan dikembangkan menjadi sebuah bisnis fashion dan aksesoris. Seringkali Asmila membeli kain dalam jumlah gelondongan yang sudah diobral dengan harga yang sangat murah karena dengan demikian akan menekan biaya produksi, dengan kepiawaian Asmila bahan baku kain yang murah tadi dapat diolah menjadi suatu produk fashion mukenah dan kerudung yang cantik. Selain itu, produk pakaiannya juga berasal dari beberapa brand yang sudah terkenal, karena permintaan pasar. Promosi dilakukan melalui media WA, BBM dan Facebook.

\section{Monitoring dan Evaluasi}

Tenant program PPK yang telah melalui proses pelatihan, pendampingan, magang, kunjungan dan konsultasi kewirausahaan setelah mahir dalam membuat bisnis plan maka tenant tersebut mulai merintis wirausaha sesuai dengan rencana usulannya. Dalam proses ini ada bantuan teknologi dan pembiayaan usaha tenant. Pembiayaan ini dibimbing dan diawasi penggunaannya oleh tim PPK diharapkan dapat membantu bisnis tenant. Adapun pemilihan wirausaha baru berdasarkan penilaian kinerja bisnis yang meliputi aspek motivasi usaha, peningkatan kemampuan kelembagaan dan SDM, peningkatan kemampuan pengembangan pasar, peningkatan kemampuan pengelolaan keuangan dan berkelanjutan usaha dapat tercapai.

Dari hasil analisis penilaian kinerja bisnis tenant, dapat disimpulkan bahwa secara pengetahuan, kemampuan, dan kapasitas produk meningkat. Namun demikian, masih banyak potensi yang dapat dieksplorasi dan ditingkatkan. Penilaian terhadap tenant dapat disajikan secara sederhara sebagai berikut:

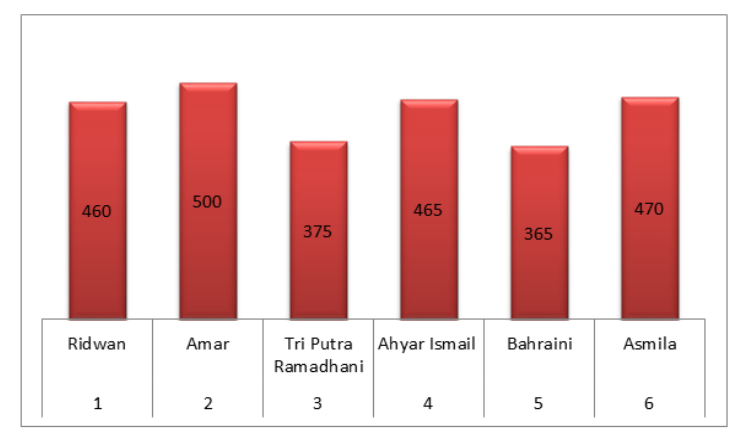

Tabel 1. Grafik Penilaian Kinerja Bisnis Tenant

Dari tabel 1, penilaian dilakukan dengan rumus Nilai $=$ skor $x$ bobot. Dapat disimpulkan bahwa PPK telah meningkatkan motivasi usaha, peningkatan kemampuan kelembagaan dan SDM, meningkatnya kemampuan teknis produksi, peningkatan kemampuan pengembangan pasar, Peningkatan kemampuan pengelolaan keuangan, dan menjamin keberlanjutan usaha

\section{SIMPULAN}

Program Pengembangan Kewirausahaan telah memberikan peningkatan terhadap pemahaman dan kemampuan tenant dalam aspek manajemen, produksi, dan literasi keuangan. Selain itu, secara kelembagaan telah terjadi transformasi yang sangat baik dengan terbukanya akses terhadap lembaga lain yang memiliki fokus terhadap 
pengembangan wirausaha mandiri. Keberlanjutan terhadap program tahap kedua akan membantu menuntaskan tenant yang akan dilatih sebagai wirausaha mandiri.

\section{UCAPAN TERIMA KASIH}

Tim Peneliti mengucapkan terima kasih kepada Ditjen Penguatan Riset dan Pengembangan Kementerian Riset, teknologi, dan Pendidikan Tinggi yang telah memberikan dana hibah Program Pengembangan Kewirausahaan, yang sangat bermanfaat terhadap penguatan Technopreneur di Universitas Muhammadiyah Palopo. Demikian juga kepada tenant dan mitra yang telah bekerja secara maksimal untuk menjamin keberhasilan Program Pengembangan Kewirausahaan.

\section{DAFTAR RUJUKAN}

Arief, M. R., Puji Astuti, P., \& Andriyanto, T. (2016). Ipteks Bagi Kewirausahaan (lbk) di Universitas Nusantara PGRI Kediri. Jurnal Dedikasi, 1-9.

Bahraini, Diana, \& Nawas, F. (2018). KRIBOU (Keripik dan Bolu Uwi) Aneka Rasa Inovasi Cemilan Sehat Khas Luwu. Bahraini, Diana, Feby Nawas KRIBOU (Keripik dan Caradde: Jurnal Pengabdian Kepada Masyarakat, 1822.

Etzkowitz, H. (1998). The norms of entrepreneurial science: cognitive effects of the new university - industry linkages. Research Policy, 823-833.

Ismail, M. (2004). Konsep Sistem Informasi Manajemen Konsep. Sumatra Utara: Perpustakan USU.

Kuratko, D. F. (2014). Kuratko, Donald. Introduction

Entrepeneurship.Canada:

SouthWestern Cengage-Learning. Canada: SouthWestern CengageLearning.

Ma'rufi, Ilyas, M., Anas, A., \& Yusrin, R. (2018). Ma'rufi, Muhammad Ilyas, Program Pengembangan Kewirausahaaan Fakultas Keguruan dan IImu Pendidikan. Caradde: Jurnal Pengabdian Kepada Masyarakat, 6776.

Ramadhan, A. (2012). Politik Ekonomi Generasi Mudalmplementasi kebijakan Gerakan Kewirausahaan Nasional di Jawa Timur. Jurnal Politik Muda, 1-8.

Sundoro, S. A., \& Ardianti, R. (2014). Entrepreneurial motivation dan Persepsi Terhadap Hambatan
Pertumbuhan Usaha Mikro dan Kecil Pada Sektor Formal di Jawa Timur. Agora, 1-5.

Widyani, W. M. (2013). Pentingnya pola Kemitraan dalam Meningkatkan Peran Kinerja Usaha Mikro, Kecil dan Menengah di Jawa Timur Periode 2006-2011 